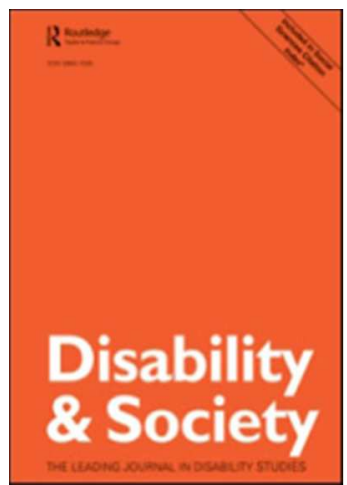

\title{
Likes, dislikes, supports and barriers: The experience of students with disabilities in University, in Ireland
}

\begin{tabular}{|r|l|}
\hline Journal: & Disability \& Society \\
\hline Manuscript ID & CDSO-2016-0167.R1 \\
\hline Manuscript Type: & Original Article \\
\hline Keywords: & $\begin{array}{l}\text { Intellectual disability, University/College, Higher educaiton, Barriers, } \\
\text { Supports }\end{array}$ \\
\hline \multicolumn{2}{|c}{} \\
\hline
\end{tabular}

SCHOLARONE ${ }^{m}$

Manuscripts

URL: http://mc.manuscriptcentral.com/cdso Email: h.j.oliver@sheffield.ac.uk 
1 The experience of students with disabilities in university

\section{Points of Interest:}

This paper helps build on research that has been done before because college students with intellectual disabilities conducted the research, analysed the data and prepared the manuscript for publication. We hoped that our research could make changes in college because it gives students a chance to give their opinion and be listened to. It also tells people in college about the barriers and supports for people with disabilities in college. We wanted to be independent by telling people things ourselves without tutors and parents. Even though we had people to help us we did the work ourselves and used our own voices. 
1 The experience of students with disabilities in university

\section{Likes, dislikes, supports and barriers: The experience of students with disabilities in university, in Ireland}

There are more students with disabilities going to college than ever before. It is important that colleges understand the experiences of students with disabilities when in university. This research project was carried out by 12 students with intellectual disabilities who are enrolled in an Irish University, under the guidance of their lecturers. It looked at four research questions: (1) What do we like about going to college?; (2) What do we dislike about going to college?; (3) What supports do students with disabilities experience to participation in college?; and (4) what barriers do students with disabilities experience to participation in college? The results show many interesting findings about what students with disabilities experience in college and this information can be used to help colleges to better support students with disabilities.

Key words: Intellectual disability, university/college, higher education, barriers, supports 
2 The experience of students with disabilities in university

\section{Introduction}

The Association for Higher Education Access and Disability (AHEAD) collect information every year about students with disabilities in Ireland. Their research shows that there has been a major increase in the number of students with disabilities in higher education since 1994 when there were only 990 students with disabilities (AHEAD, 2016).

Research about students with disabilities is important because there are a lot of students with disabilities and it would be useful for authorities to understand the needs of these students. Research in Ireland reveals the following statistics, for example:

- According to the 2011 Census in the Republic of Ireland, 595,335 people in Ireland have disabilities. That figure represented $13 \%$ of all of the people in Ireland at the time (CSO, 2012).

- According to the Higher Education Authority there were 214,694 students enrolled in higher education in Ireland in the 2014/2015 academic year (HEA, 2015).

- In 2014/2015 there were 10,733 students with disabilities in 27 higher education institutions in Ireland. This includes students attending universities, institutes of technology and other institutions such as art colleges and teacher training colleges. This represents $5 \%$ of the total student population (AHEAD, 2016).

- $25 \%$ of people with disabilities aged 15-49 were educated to third-level. This is compared to $39 \%$ of the general population (CSO, 2012). A smaller proportion of people with disabilities therefore participate in higher education than people without disabilities.

The rise in the number of students with disabilities in higher education means that higher education institutions (HEIs) may face challenges in supporting these students. Research in this area can show HEIs how they can help.

\section{College Experience}

\section{What is college like for students in general?}

Some researchers have studied what it is like to be a student in higher education. Students in one research study described five types of activities as a student: academic (e.g. going to class, studying), informal (e.g. socialising with friends, exercising), formal extracurricular 
3 The experience of students with disabilities in university

(e.g. students clubs), work (e.g. part-time jobs) and university sponsored events (e.g. sport events) (Ekelman, Bazyk, \& Bazyk, 2013).

The Irish Survey of Student Engagement (ISSE) asked first year undergraduates, final year undergraduates and postgraduate students about their experiences of higher education. More than 27,000 students from 30 HEIs took part in 2015. The results show that almost all students spend some time outside of class studying each week and that the highest number of students (34.7\%) spend between 1 and 4 hours studying every week. These are some of the other activities that students engage in: group work in class (54\%), giving a presentation (34\%), talking to others about things they learned in class (59\%), reading books or journal articles (89\%) and doing assignments of less than 1000 words (73\%), between 1000-5000 words $(87 \%)$ or more than 5000 words (38\%) (ISSE, 2015). A study that researched transitions to higher education for all students found that the biggest difficulties were: paying fees or other costs, knowing what standard is expected, the difficulty of the course, juggling work and study, timely completion of coursework, finding time for other interests and balancing personal relationships (McCoy, Smyth, Watson \& Darmody, 2014). These studies tell us that there are a lot of different activities in college and that there are things about being a student that are difficult for all students, whether or not they have a disability.

\section{What makes college harder for students with disabilities?}

Although more people with disabilities now attend college than before, a smaller proportion of them graduate from college when compared to people without disabilities (Getzel \& Thoma, 2008). It is therefore important to understand what people with disabilities need when they are in college so that they can have a more positive experience.

\section{Barriers to participating in college}

The barriers to participating in college for people with disabilities have been studied by many researchers. In one study (Hong, 2015), sixteen college students with various disabilities kept a journal about their student experience for 10 weeks. Students in this study often described college as stressful. These are some of the things they found stressful about college life: the physical environment, distractions, side effects of medication, feeling tired (less time to do work, skipping class, less socialising), feeling like a burden, feeling they need to prove themselves, accepting their limitations, lack of time-management skills, managing deadlines when lots of work is due at the same time, waking up on time for class, social stigma (e.g. being resented by friends) and self-consciousness. The attitudes of teaching staff were also 
4 The experience of students with disabilities in university

reported as a barrier. Students felt like they were being judged and were embarrassed by teaching staff. Students didn't want teaching staff to think they were less able to do their work. Some students thought they were treated differently to classmates without disabilities. Some students felt uncomfortable telling staff about their disability and the things that would help them.

Another study interviewed 10 university students with disabilities (Ekelman et al., 2013) and found that students considered academic activities stressful and felt they spent most of their time doing college work. They spoke about feeling anxious and overwhelmed. A study by Sachs and Shreuer (2011) compared how higher education students with various disabilities $(\mathrm{n}=170)$ performed academically and got involved in college life in comparison to people without disabilities ( $\mathrm{n}=156)$. They found that students with disabilities needed to spend more time working to get the same results as students without disabilities. Students with disabilities took part in class activities and extracurricular activities like music and art less than students without disabilities.

One study researched the things that are hard for students with Attention Deficit Hyperactivity Disorder (ADHD) and Autistic Spectrum Disorder (ASD) in universities and institutes of technology (Clince, Nolan \& Connolly, 2015). Challenges for students with ADHD were concentrating when studying, getting started with study, putting things off (procrastination), starting writing and dealing with work overload. People with ASD found it hard to manage anxiety and negative thoughts. Managing stressful situations, concentrating in lectures and procrastinating were also difficult for people with ASD.

Although many of the challenges experienced by students with disabilities can be experienced by all students it may be more difficult for students with disabilities to cope with these challenges in addition to managing their disability.

\section{Supports to participating in college}

A review of the research shows us that there are many barriers to succeeding in higher education for people with disabilities. This means that students with disabilities may need extra supports to help them to succeed in college.

Getzel \& Thoma (2008) did a study with a group of 34 college students with a variety of disabilities (visual, orthopaedic, other health impairment, deafness, specific learning disability, emotional disturbances) from the United States. They found that students identified 
5 The experience of students with disabilities in university

problem solving, self-awareness, self-management, looking for services on campus, developing support systems on campus and having a positive relationship with your professor as supports that lead to success in higher education. Developing these skills and supports is important for students with disabilities to help them to stay in education and to graduate (Harris \& Robertson, 2001; Jameson, 2007).

In Ireland, AHEAD (2015) have researched some of the supports and reasonable accommodations that can make college life easier for people with disabilities. For example, $79 \%$ of students with disabilities receive exam accommodations such as extra time to complete exams, different venues (e.g. low distraction venue), the use of a computer and the use of a scribe or reader.

These studies tell us that there are some supports that can make being a student easier for people with disabilities.

\section{Rationale for our research}

There has been very little research done by college students with intellectual disabilities about their own likes, dislikes and supports and barriers to college life, which is why our research project tries to answer the following four questions:

1. What do we like about going to college?

2. What do we dislike about going to college?

3. What supports do students with disabilities experience to participation in college?

4. What barriers do students with disabilities experience to participation in college?

We did this research for four reasons:

1. We thought people would be interested. The main people we thought would be interested are other students, parents, teachers and college management.

2. We hoped that our research might lead to changes in college because it gives students a chance to give their opinion and be listened to. It also tells people in college about the barriers and supports for people with disabilities in college.

3. We hope that we encourage other people with disabilities to do similar research. 
6 The experience of students with disabilities in university

4. We wanted to be independent by telling people things ourselves without tutors and parents. Even though we had people to help us we did the work ourselves and used our own voices.

\section{Writing style of paper}

We decided to write the paper in accessible format because we wanted to show people with disabilities, researchers, teachers, doctors, and other members of society that people with intellectual disabilities can not only take part in research but can also analyse research data and think critically. The writing style of the paper helps us to show the reader that people with intellectual disabilities had a big part in writing the research paper. During our time in college we learned that the voices of people with intellectual disabilities are not often heard and that at times people with intellectual disabilities are not taken seriously because of their disability. For this reason, it is important that the voices of people with disabilities are included in research projects, not only through taking part in research projects but also by deciding how research findings are shared with society. This way society can start to see people with disabilities, especially intellectual disabilities, as having the ability to think critically, just like someone without an intellectual disability.

\section{Terminology}

University \& College: In Ireland, 'college' is commonly used to refer collectively to universities and institutes of technology. In our paper we use the word college because that is what makes most sense to us, even though the research was carried out in a university. You will see the word university and college used when we talk about other research that has been done in different parts of the world. We made sure to use the same terms from the research articles that we consulted so that we were reporting information from the literature correctly.

Students with disabilities: We decided as a group to refer to students with disabilities as students first and their disability second. It is very common that when society sees someone with a disability they make assumptions about them. For example, they are not smart enough, they could never graduate from college, they could never be an athlete, or they could never have a paying job. But most of the time a person with a disability can do anything they want. It is often the case that society limits them, either through the physical environment, social networks, personal relationships, or the community (this is called the social model of disability). 
7 The experience of students with disabilities in university

\section{Methods}

\section{Participants}

Twelve university students with intellectual disabilities participated in and completed this research project, under the guidance of our three lecturers. We were enrolled in a two-year college certificate programme at a university in Ireland. Three men and nine women that took part in the research project. The age range was 19 to 39 with the average age being 26 years. We all have some form of an intellectual disability, we all travelled to college independently, and none of us use a wheelchair. The research project took place during our Research Methods module. As part of our Research Methods module we had to conduct a research project. We thought it would be interesting to look at what may be some of the supports and barriers that students with disabilities face when they are going to university. Our research project took place over five class periods. Each class was two hours long and took place on campus.

\section{Procedure}

In our study we used a participatory research design that involved photovoice, and nominal group technique. We talk about each of these below:

Participatory research design: There are many different styles of research, for this study we used a participatory research design. That is when the participants of the research take an active role in the project like coming up with the research questions, figuring out how to best collect data, analysing the data, and informing the public about your research findings.

Photovoice: We used the photovoice method to collect and analyse our data. Photovoice is an accessible research method used to include people with intellectual disabilities in research and it is becoming more common in research in this field (Hergenrather, Rhodes, \& Bardhoshi, 2009; Wang, Cash, \& Powers, 2000; Aldridge, 2007; Jurkowski, 2008).

Nominal Group Technique: We also used a research method called nominal group technique, known as NGT. NGT is when, as a group, you make a list of things that is important to you and related to the research questions. Each person then gets to vote on their top choices (Gallagher et al., 1993; Delbecq \& Van de Ven, 1971; Delbecq, Van de Ven, \& Gustaffson, 1975; Hares, Spencer, Gallagher, Bradshaw, \& Webb, 1992). Using NGT made sure that everyone was able to give their opinions on what they felt was most important when trying to make sense of our findings. 
8 The experience of students with disabilities in university

The data-collection methods for our project were as follows:

Week 1: We spent one class period learning how to use the digital cameras. Each student was given their own digital camera to take photos.

Week 2: We broke-up into three groups and walked around campus taking pictures of what we liked and disliked about going to college. Each group had one lecturer in the group if we needed any help.

Week 3: We broke-up into three groups and walked around campus taking pictures of barriers and supports around campus for people with disabilities. Each group had one lecturer in the group if we needed any help.

Insert Figure 1 here.

Week 4: The lecturers developed the pictures we took and we spent the whole class analysing the first research questions. In our groups we put the pictures on the table and picked which pictures helped us answer what we like and dislike about college. In our small groups we chose the pictures we thought were most important to put on our posters. We put the pictures on poster boards and discussed what we wanted to say about each picture. We then wrote a brief description explaining why that picture was important to include on the poster board. We took turns to write underneath the photos. We presented the poster to the class. After each group presented their poster we then looked at what things were similar between groups and we developed a list of all of the items. We made two lists: 1) what we like about college and 2) what we dislike about college. After the lists were developed each of us voted with stickers on our top three most important items on both lists. We then discussed our results and wrote about what the results mean and why they are important.

Week 5: We followed the same steps as we did in Week 4 to answer the research questions about supports and barriers for people with disabilities in college.

Insert Figure 2 here.

After the group analysed the data we presented the findings from the project at a research seminar that was held at the university. We invited important people like the Head of the School of Education, the director of disability services, professors, administrative staff and staff from different student services to come to our research presentation. A total of 70 staff members from around the university attended the seminar. At the seminar, we presented 
9 The experience of students with disabilities in university

to university staff about the barriers and supports that we identify for students with disabilities and provided them with suggestions on how to improve the experiences of students with disabilities who go to university. Since the data in our study was collected and analysed by students with disabilities (this type of work is called co-production) we wanted to make sure to share our findings with important staff members of the university, in the hope that future policies can be designed to make sure that they are actually meeting the needs of students with disabilities.

\section{Analysis}

The analysis drew from 2 data collection sources: 1) poster boards (photovoice) and 2) voting (NGT). The photovoice helped guide the voting process (NGT). First, for the poster boards we took all of the items listed on the poster boards and transferred them to one list. We then took this list and grouped similar items together and developed what are called themes (Corbin \& Strauss, 1990). This helped us understand the data better because we had grouped similar things together. We then individually voted on which themes we thought were most important. We all got three votes for each list. In total we developed four lists (e.g. what we like about college, what we dislike about college, supports for people with disabilities in college, and barriers for people with disabilities in college). After we all had an opportunity to vote individually, we counted all of the votes to see which the three most popular items on each list were. We will describe our results below for each of the four lists that were created.

\section{Results}

For the research project our findings showed the following results:

\section{Research Question 1: "Things we like about college life”}

For things we like about college life we found the following factors to be the most important in our analysis: socialising, graduating, learning, technology, sports and being healthy, and architecture. Table 1 shows how many votes each theme received.

Insert Table 1 Here

The theme that got the highest number of votes from the group was socialising ( 8 votes). For socialising it was reported that making friends, having fun, hanging out with friends, keeping life going, being good friends, meeting new people, getting along with everyone and not leaving friends out, were all important to the group. The students also liked talking to people around college, like other students, professors, staff from the sports centre 
10 The experience of students with disabilities in university

and the cafeteria. Since college is in the city centre, students get to walk about the city during lunch breaks, go to different shops or have lunch at different restaurants in the city.

The theme of graduating got 6 votes. The group looked forward to celebrating time in college, getting their college certificates, getting jobs, preparing for the future, looking back at college experiences, and having dreams come true. For example, one member of the group talked about how her dad is a professor and all three of her siblings went to college and now she gets to be just like them - graduating from the same college as her siblings. The students talked about how graduating from college would help them find a good job they would like and that would pay more money so they could be more independent.

The theme of learning got 5 votes. The results showed that the group liked learning in college. The students liked reading and learning how to do new things. For example, many people in the group liked learning about maths and sciences because a lot of them never got a chance to learn about these subjects before. Supporting new people in college with the new things they learned was also something that the group liked. They also liked using their new knowledge to prepare for what comes after college, such as for getting a job and being more independent. Developing communication skills was also something that the group liked. There are many chances to learn in college and the students valued having the opportunity to learn new things. It helped them to develop as people and as learners. This was seen as important for life after college, to move on to other courses, to get employment and for their personal lives in the future.

The theme of technology was reported as something that the group liked and this theme got 5 votes. The group liked talking about technology, working on computers, fixing computers, looking up information, studying on computers, emailing friends, playing games, YouTube, listening to music, learning new things in life and using email to check what homework you may have. The chance to use technology in college was seen as good for learning and for other parts of the students' personal lives as well.

The theme of sports and being healthy got 4 votes. The group talked about how they liked coming to college and using the sports centre to exercise and get healthier. Some people in the group talked about their personal goals to become fit and how they used the treadmill in the sports centre to help them with their goals. One student used the swimming pool in the sports centre to help her train for her swimming competitions. Another student talked about 
11 The experience of students with disabilities in university

how he has joined college sports teams and volunteered in events that the sports centre puts on.

The theme of architecture got 2 votes. Some people in the group talked about how they liked coming to college because the campus is really pretty. The buildings on campus were very historical and nice to look at.

\section{Research Question 2: "Things we dislike about college life”}

For the second research question we found the following six themes to be most important in relation to what we don't like about college. The six themes are: studying/exams, road works/traffic/trains, ramps help some people but are a hazard to others, getting up early, sports, and birds. Table 2 shows how many votes each theme received.

Insert Table 2 Here

The theme of studying/exams got 8 votes. It was found that students can get stressed and that other people could help more, for example by reading in a way that they can understand. Students felt that there was sometimes too much work in one week and that new students may find it stressful.

The theme of road works/traffic/trains got 8 votes. The students found that things could get too noisy with all the construction that is happening around campus. This noise can be a distraction. It was reported that sometimes it made it difficult to hear what the instructor was saying. Students felt that there were often too many people on the road. Other people may find it hard at times because this can cause students to be stuck in traffic and late for class. Students had to sometimes plan different routes to get into college.

The theme of ramps help someone people by are a hazard to others got 6 votes. It was revealed that while ramps are very helpful to some people with disabilities, they may also prove to be a hazard to other people with disabilities. For example, the group talked about how ramps might be a hazard for people who are blind as they might trip over the ramps when walking around campus. The students thought that ramps should be positioned so that they are not a hazard for people who have trouble seeing.

The theme of getting up early got 5 votes. The students found that getting up early was something that the group did not like. They stated that it caused them to get tired during the day. If students had a test they might stay up late and study and still have to get up on 
12 The experience of students with disabilities in university

time to make it into college for class. The students talked about how they are not morning people and that they need sleep. Students spoke about the need for balance in their life so that they can get eight hours of sleep a night and be on time for class.

The theme of sports got two votes. Some of the students did not like to take part in sports in college because they were not interested in doing sports. Most students liked to do sports, but for those students who did not like sports they particularly did not like it when they were made to take part in sport activities because they do not like running around.

The theme of birds got one vote. When students made their poster boards a couple of poster boards had pictures of birds on campus. Students talked about how they did not like birds because they were afraid of them and found them scary.

\section{Research Question 3: "Supports to participating in college"}

We found the following factors to be the most important in our analysis when examining what supports are around campus for people with disabilities: classroom support; ramps, automatic doors and lifts; join in sporting games; services; going to reception for information and help; signs and braille maps; emergency equipment and stations. Table 4 shows how many votes each theme received.

Insert Table 4 here

The theme of classroom support got 8 votes. Classroom supports that were mentioned were getting supports from friends, professors and scribes. If a student gets stuck they will have support from these people to ask questions. Professors in college can support students with their work. Students can ask their professors questions or for more help to understand the lesson. Classmates were seen as another support to participating in college. It is important for classmates to get along, respect each other, and support each other with their coursework and college life. Classmates can support each other when they are feeling anxious, or having personal problems. Tension between classmates can cause problems for students wanting to stay in college and can also affect their learning.

The theme of ramps, automatic doors and lifts got 7 votes. The group talked about how ramps, automatic doors and lifts can help people who use wheelchairs or crutches to get around college. These things can help improve access for students with disabilities getting into buildings that are not on ground level and can make sure that students with disabilities can actually get to their lectures without any problems. 
13 The experience of students with disabilities in university

The theme of joining in sporting games got six votes. Sport was seen as a place where students with disabilities can socialize, keep healthy, participate in college, make friends, try new sports, and get better at the sports they like. Sport was also seen as a way for students to improve their communication and teamwork skills.

The theme of services received 5 votes. There are a lot of services on campus that students with disabilities can use if they need help or support. These include the health service, the disability service, the counselling service and the physiotherapist. These supports can help students with a disability to stay in college and make sure they graduate.

The theme of going to reception for information and help got 4 votes. Students with disabilities can get support by seeking advice or directions to a place like a classroom by asking college staff that work at reception desks. Also if students find an item that another student has lost they can bring it to a reception desk so the owner can go and collect their lost item.

The theme of signs and braille maps got 2 votes. These were seen as most important for students who have trouble seeing so that they can be supported when trying to find their way around campus. Without signs and braille maps students will not be able to make their way to class and participate in college activities because they will not know where to go and will always have to ask other people for help.

The theme of emergency equipment and stations received 1 vote. Students talked about how emergency stations and equipment are important for students with physical disabilities and students who are blind or have trouble seeing. If there were an emergency on campus students would be supported by college in making sure they are kept safe for any emergency situation that might happen.

\section{Research Question 4: "Barriers to participating in college”}

For barriers to participating in college our research showed the following themes to be most important: Hard to open doors, steps and stairs, things too high up, cobble stones, signs are hard to read, going through the main gates. Table 3 shows how many votes each theme received.

Insert Table 3 Here 
14 The experience of students with disabilities in university

Three themes received the same number of votes ( 8 votes) and were thought to be equally important. The top-voted barriers for students with disabilities in college were: hard to open doors, steps and stairs, and things too high up.

For the theme of hard to open doors the group felt that handles and latches around campus might be too high to reach. Sometimes people have to get help to open doors which is a barrier when they are trying to be independent on campus. For students who use wheelchairs they might not be able to open doors if they are not automatic. The students talked about how it would be better if all doors around college were automatic, especially because some doors do not have handles which can make it hard for people with disabilities to open.

For the theme of steps and stairs the group found that steps and stairs might be difficult for people who use a wheelchair or for people who use crutches. Steps are hard to get up as they might be too steep for some people. The students talked about how people who are blind might need help going up stairs, that steps and stairs can be dangerous for some people, and that they can also affect a person with a disability's freedom to be independent because they would need help getting around campus.

For the theme of things too high up students found that people with disabilities might have trouble reaching the light switches when entering a classroom or bathroom. If someone was using crutches it would be very difficult for them to reach up for light switches, door handles, lockers or shelves. They would have to always ask for help which could affect them being independent. The group felt that things should be kept at eye level or lower so that everyone can reach.

The theme of cobble stones received 4 votes. The group thought that cobble stones made the campus look nice, but that they are not helpful for students who use wheelchairs or for students who are blind because the ground is uneven and you can easily trip and hurt yourself.

The themes of signs are hard to read and going through the main gates got 2 votes each. It would be useful for students who are blind to have every sign on campus include braille. The main entrance to campus is a gate. Getting through the main gates can be tricky because they are narrow and there are always a lot of people trying to go through them to get to class. The narrow gate and the area being crowded all the time can make students nervous. 
15 The experience of students with disabilities in university

\section{Discussion}

This paper looked at four research questions: (1) What do we like about going to college?; (2) What do we dislike about going to college?; (3) What supports do students with disabilities experience to participation in college?; and (4) what barriers do students with disabilities experience to participation in college? Our findings showed what students with intellectual disabilities like and dislike about going to college and these things should be considered when organizing courses for others students with disabilities in the future.

Our findings support and build on past disability research. We talk about how our research project fits in with the disability community and human rights for people with intellectual disabilities below.

\section{Disability Community}

An interesting finding of our study was that students focused more on physical barriers that could affect a person's ability to participate in university life; while at the same time they identified social and personal factors as key supports needed to be successful in college. We should also mention that when we first started the study it was supposed to focus on the college experience of students with intellectual disabilities, but once we started to collect data it became clear that we were collecting data to support all students with different types of disabilities. This is an important finding because researchers who study disability culture (disability culture is a group of people who have a disability and want to have relationships with other people with disabilities because they experience life the same way) often do not include people with intellectual disabilities as being part of the disability community (Beart, 2005) because a lot of people in society still do not see people with intellectual disabilities as being humans with feelings, dreams, goals, and desires just like other people with or without disabilities (Goodley, 2001; Ferguson \& Ferguson, 2009; Spassiani \& Friedman, 2014).

In our study the group was focused on not only the experience of students with intellectual disability, but also students with all types of disability. Two researchers by the name of Longmore (2000) and Scotch (1998) talk about how people who have a disability often feel connected to other people with a disability because they may have gone through the same kinds of experiences. Our group felt as though they were part of the same disability community as students with physical disabilities and they wanted to make sure the research 
project helps to support their right to equal access to education as well. Our findings show that future research should look at how people with intellectual disabilities may be included in disability culture as more people with intellectual disabilities may feel the same connection as our group does to the disability community. People with intellectual disabilities need to be part of the disability community because they understand what it is like to feel alone, to not have people believe in their abilities, and have everyone think you cannot be independent. As more people with intellectual disabilities start to live in the community it is important that people with all types of disabilities believe in and support people with intellectual disabilities. In this way, increased participation and success in important domains, such as higher education, can become a reality.

\section{Human Rights}

The Universal Declaration of Human Rights (United Nations, 1945) was created to make sure that everyone in the world is treated equally no matter what religion you believe in, what language you speak, where you live, what your nationality is, or if you have a disability. However, even with the Universal Declaration of Human Rights people with disabilities were still being denied their rights. For this reason the United Nations' Convention on the Rights of Persons with Disabilities (also known as the CRPD) was created in 2006 and written to make sure that all people with disabilities have equal access to their human rights. The CRPD has a right that is called 'Education for All'. This means that children, adolescents, and adults have the right to access education that is inclusive and of the same quality as people without disabilities. This education should help people with disabilities to learn all of the skills they need in order to participate fully in society and should continue into adulthood if the person wants to continue learning. The CRPD also states that all people with disabilities have the right to employment where they are given the same opportunities and wages as people without disabilities (United Nations, 2006). Although the CRPD has helped people with disabilities, there are still a lot of people with intellectual disabilities who are still denied their right to education and employment. This may be because society does not see the importance of educating people with intellectual disabilities or preparing them for employment because, according to the current model, people with intellectual disabilities cannot be educated and will always be dependent on other people to live. This can be seen in how there are very few systems in place that support people with intellectual disabilities to attend further education or that support them with employment opportunities. 
17 The experience of students with disabilities in university

People with intellectual disabilities do want to be independent and that is why it is so important that they get access to high quality education so that they can be competitive for jobs just like other university graduates. We as a group wanted to try to help all students with disabilities because colleges have more people with disabilities now than before. We think this is because people with disabilities want to learn more and there are more chances for people with disabilities to go to college than there were 20 years ago. This means that colleges need to do more to help people with disabilities to understand things. There can be barriers to going to college so there should be supports too. Colleges can do more to understand everyday struggles and barriers for people with disabilities to make sure that they not only can go to college but that they can successfully complete their programme. Past research has shown that students with intellectual disabilities who go to college are more likely to find paid employment, need fewer supports in the community, and earn more money than do people with intellectual disabilities who do not go to college (Hart, 2006). That is why this research is so important because it directly helps people with disabilities to go to college and be successful.

Our findings also relate closely to what other research has found about students with disabilities who go to college. We talk about some of our important findings below.

\section{Academic}

The ISSE report (ISSE, 2015) tells us that almost all students spend some time every week studying. Other researchers found that studying can be stressful (Ekelman et al., 2013; Clince et al., 2015) and we found this in our study too. We also found out about the things that can make study less stressful: reading things in a way we understand, classroom support, friends, teachers and scribes. Colleges can make sure they have these supports in place and available to students with disabilities so that when they feel stressed they know who to go to for help. Our findings also showed that students with intellectual disability may be no different than other students who don't have a disability. For example, students reported that they like attending college because they like to learn new things and understand that a college education will help develop independent life skills and will increase your chances of getting a better paying job, but students dislike studying, taking exams and getting up early, which is common for students to feel regardless of disability. 
18 The experience of students with disabilities in university

\section{Social}

Socialising with friends is one of the things we found students liked about college in our research. We also found that friends are a support for students with disabilities. In Ekelman et al.'s (2013) study socialising was seen as one of the main activities in college. In McCoy et al.'s (2014) study about all students starting higher education they found that balancing personal relationships is hard. In Hong's study (2015) if students were tired they spent less time socialising and sometimes they felt like they were seen as a problem and experienced social stigma. This is important because it means that even though friends and social support help people with disabilities in college it can also be hard for people with disabilities to make friends and spend time with them. Our findings showed that social support in college is very important so that students do not drop out of college and for this reason colleges should make sure that students with disabilities feel welcome and are treated the same as students without disabilities.

\section{Graduating}

Graduating was something that was important to students in our study. We think that people with disabilities going to college and graduating is important for many reasons: people with disabilities have the same rights to education as everyone else, it means that people with disabilities are not left out, it makes it easier to get a job or move on to further education, it means people can reach their goals and plan for their future and gives people more opportunities. Even though graduating is important other researchers found that fewer people with disabilities attend and graduate from college (Eckes \& Ochoa, 2005; Getzel \& Thoma, 2008; CSO, 2012). It is important that people with disabilities go to college so they can get better jobs and make money just like people without disabilities. We know that people without disabilities who go to college are more likely to find good jobs and make good money (Hart, 2006). Colleges should make sure that they have the right supports in place for students with disabilities so that they have the same employment opportunities.

\section{Physical Barriers}

Most of the barriers to going to college for students with disabilities that we found in our study were physical barriers such as steps, doors and uneven surfaces. Hong's study (2015) found that physical barriers were one of the things that made college stressful. That study also found that distractions were a stressor for students with disabilities. In our study students did not like the distraction of noise from trains and traffic. Even though colleges do not have 
19 The experience of students with disabilities in university

control over city traffic and construction they can still try to make sure that the lecture rooms are not near busy city streets so that students with disabilities do not get stressed out or distracted from all the noise. We also found that some students in our research project reported ramps to be hazardous for students who are visually impaired or blind, while other students reported steps and stairs to be a barrier for wheelchair users. The group talked about how each student has their own needs and it is important that the university understand what each student needs to make sure they are successful and safe while on campus.

\section{Professors}

Hong's study (2015) found that one of the barriers for students with disabilities was attitudes of teaching staff. The study found that some students felt judged by their teachers and didn't feel comfortable asking for their help. In our study we found that the professors were a support for students with disabilities. This finding is just like the finding that Getzel \& Thoma (2008) reported in their study about how having a positive relationship with your professor was seen as a support that leads to success in college. Professors should not make students with disabilities feel uncomfortable when they need to ask for help. They are there to help all students no matter if they have a disability or not. Colleges should make sure that their professors' attitudes towards disability do not affect how they teach and interact with students with disabilities. Students should never be afraid to ask for help if they need it. There is no such thing as a silly question and every question students have will help them understand their course work better.

\section{Different Supports}

Some of the supports that we found were also found in Getzel \& Thoma's study (2008) such as using services in college, having support from your professor and having social supports (friends) on campus. Readers and scribes were another support that we found in our study and these are things that many students with disabilities receive as exam accommodations (AHEAD, 2015). We also found some supports that are different to other research such as joining in sporting games.

\section{Conclusion}

This paper can be used to tell colleges how to better provide supports for students with disabilities. Students in another college did a photovoice research project and it led to changes being made in their college (e.g. changes in signage, giving training to student union 
20 The experience of students with disabilities in university

staff, removing overgrown shrub) (Agarwal, Moya, Yasui \& Seymour, 2015). Even though there were only 12 students that took part in this study it is a good starting point for colleges to start thinking about what students with disabilities like, dislike, and what barriers and supports they experience. More people with disabilities need to be part of research so we can figure out how to best support students in the way they want to be supported. Sometimes people think they know what is best for people with disabilities, but this is not true. People with disabilities know what is best for them. They are the best people to ask what supports they need. People with disabilities need their opinions and thoughts to be part of research because research is used by colleges to see how they should make supports and services better for their students. That is why it is so important for people with intellectual disabilities to be part of research so that their voices, experiences, opinions and concerns can be heard. This will make sure that people with intellectual disabilities are given lots of opportunities to be in control of their lives (Spassiani \& Friedman, 2014). Dr. Seuss said "Only you can control your future" that is why it is so important that people with intellectual disabilities start speaking up about what supports they need in college so they can have a successful future just like people without disabilities. 
21 The experience of students with disabilities in university

\section{References}

AHEAD (Association of Higher Education Access and Disability) (2015). Numbers of students with disabilities studying in higher education in Ireland 2014/15. Dublin: AHEAD Educational Press.

Aldridge, J. (2007). Picture this: The use of participatory photographic research methods with people with learning disabilities. Disability \& Society, 22, 1-17.

Bart, S. (2005). "I won’t think of meself as a learning disability. But I have": Social identity and self-advocacy. British Journal of Learning Disabilities, 33, 128-131.

Bickenbach, J.E. (2009). Disability, culture and the UN convention. Disability and Rehabilitation, 31, 1111-1124.

Clince, M., Nolan, C. \& Connolly, L. (2015). "Recommendations for supporting students with ADHD and Asperger's Syndrome in Higher Education Environments". Paper presented at Universal Design for Learning: A License to Learn, AHEAD Conference, Dublin, March 19 - 20.

Corbin, J. M., \& Strauss, A. (1990). Grounded theory research: Procedures, canons, and evaluative criteria. Qualitative Sociology, 13(1), 3-21. http://dx.doi.org/10.1007/BF00988593

CSO (Central Statistics Office) (2012). Profile 8: Our bill of health. Dublin: Central Statistics Office.

Delbecq, A. L., \& Van de Ven, A. H. (1971). A group process model for problem identification and program planning. The Journal of Applied Behavioral Science, 7(4), 466-492. http://dx.doi.org/10.1177/002188637100700404

Delbecq, A. L., Van de Ven, A. H., \& Gustafson, D. H. (1975). Group techniques for program planning: A guide to nominal group and Delphi processes. Glenview, IL: Scott, Foresman

Eckes, S., \& Ochoa, T. (2005). Students with disabilities: Transitioning from high school to higher education. American Secondary Education, 33, 6-20. 
22 The experience of students with disabilities in university

Ekelman, B., Bazyk, S., \& Bazyk, J. (2013). The relationship between Occupational Engagement and Well-Being from the Perspective of University Students with Disabilities. Journal of Occupational Science, 20(3), 236-252.

Ferguson, P.M., \& Ferguson, D.L. (2009). Winks, blinks, squints and twitches: Looking for disability, culture and self-determination through our son's life eye. Scandinavian Journal of Disability Research, 3, 71-90.

Gallagher, M., Hares, T., Spencer, J., Bradshaw, C., \& Webb, I. (1993). The nominal group technique: A research tool for general practice? Family Practice, 10(1), 76-81. http://dx.doi.org/10.1093/fampra/10.1.76

Getzel, E.E., \& Thoma, C. A. (2008). Experiences of college students with disabilities and the importance of self-determination in higher education settings. Career Development for Exceptional Individuals, 2, 77-84.

Goodley, D. (2001). "Learning difficulties," the social model of disability and impairment: Challenging epistemologies. Disability \& Society, 16, 207-231.

Hares, T., Spencer, J., Gallagher, M., Bradshaw, C., \& Webb, I. (1992). Diabetes care: Who are the experts? Quality in Health Care, 1(4), 219224.http://dx.doi.org/10.1136/qshc.1.4.219

Harris, R., \& Robertson, J. (2001). Successful strategies for college-bound students with learning disabilities. Preventing School Failure, 45, 125-131.

Hart, D. (2006). Research to practice: Postsecondary education options for students with intellectual disabilities. Research to practice series, Institute for Community Inclusion. Paper 6.

Hergenrather, K. C., Rhodes, S. D., \& Bardhoshi, G. (2009). Photovoice as community-based participatory research: A qualitative review. American Journal of Health Behavior, 33, 686-698.

Higher Education Authority (2015). Higher education 2014/15: Key facts and figures. Dublin: Higher Education Authority. 
23 The experience of students with disabilities in university

Hong, B., S., S. (2015). Qualitative analysis of the barriers college students with disabilities experience in higher education. Journal of College Student Development, 56, 209226.

ISSE (Irish Survey of Student Engagement) (2015). The Irish Survey of Student Engagement: Results from 2015. Dublin: ISSE.

Jameson, D. R. (2007). Self-determination and success outcomes of two-year college students with disabilities. Journal of College Reading and Learning, 37, 26-46.

Jurkowski, J. M. (2008). Photovoice as participatory action research tool for engaging people with intellectual disabilities in research and program development. Intellectual and Developmental Disabilities, 46, 1-11.

Longmore, P. (2000).Disability policy and politics: Considering consumer influences. Journal of Disability Policy Studies, 11, 36-44.

McCoy, S., Smyth, E., Watson, D., \& Darmody, M. (2014). Leaving School in Ireland: A Longitudinal Study of Post School Transitions. ESRI Research Series 36. Dublin: ESRI.

Sachs, D., \& Schreuer, N. (2011). Inclusion of Students with Disabilities in Higher Education: Performance and participation in student's experiences. Disability Studies Quarterly, 31(2).

Scotch, R. (1988). Disability as the basis for a social movement: Advocacy and the politics of definition. The Journal of Social Issues, 1, 159-172.

Spassiani, N.A., \& Friedman, C. (2014). Stigma: Barriers to culture and identity for people with intellectual disability. Inclusion, 2, 329-341

United Nations. (2006). Convention on the Rights of Persons with Disabilities and Optional Protocol.

Wang, C. C., Cash, J. L., \& Powers, L. S. (2000). Who knows the streets as well as the homeless? Promoting personal and community action through photovoice. Health Promotion Practice, 1, 81-89. 


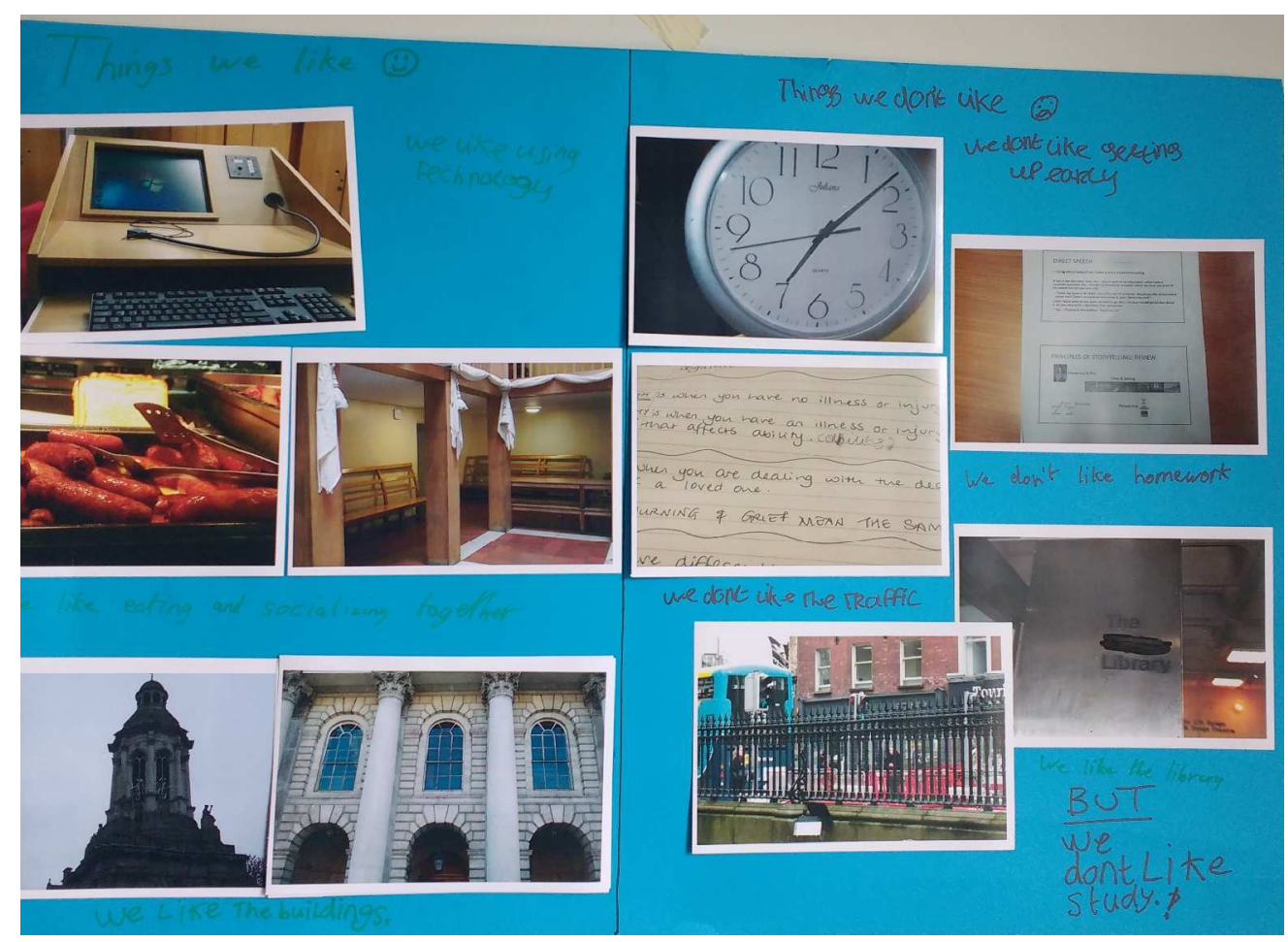

$807 \times 587 \mathrm{~mm}(96 \times 96 \mathrm{DPI})$

URL: http://mc.manuscriptcentral.com/cdso Email: h.j.oliver@sheffield.ac.uk 


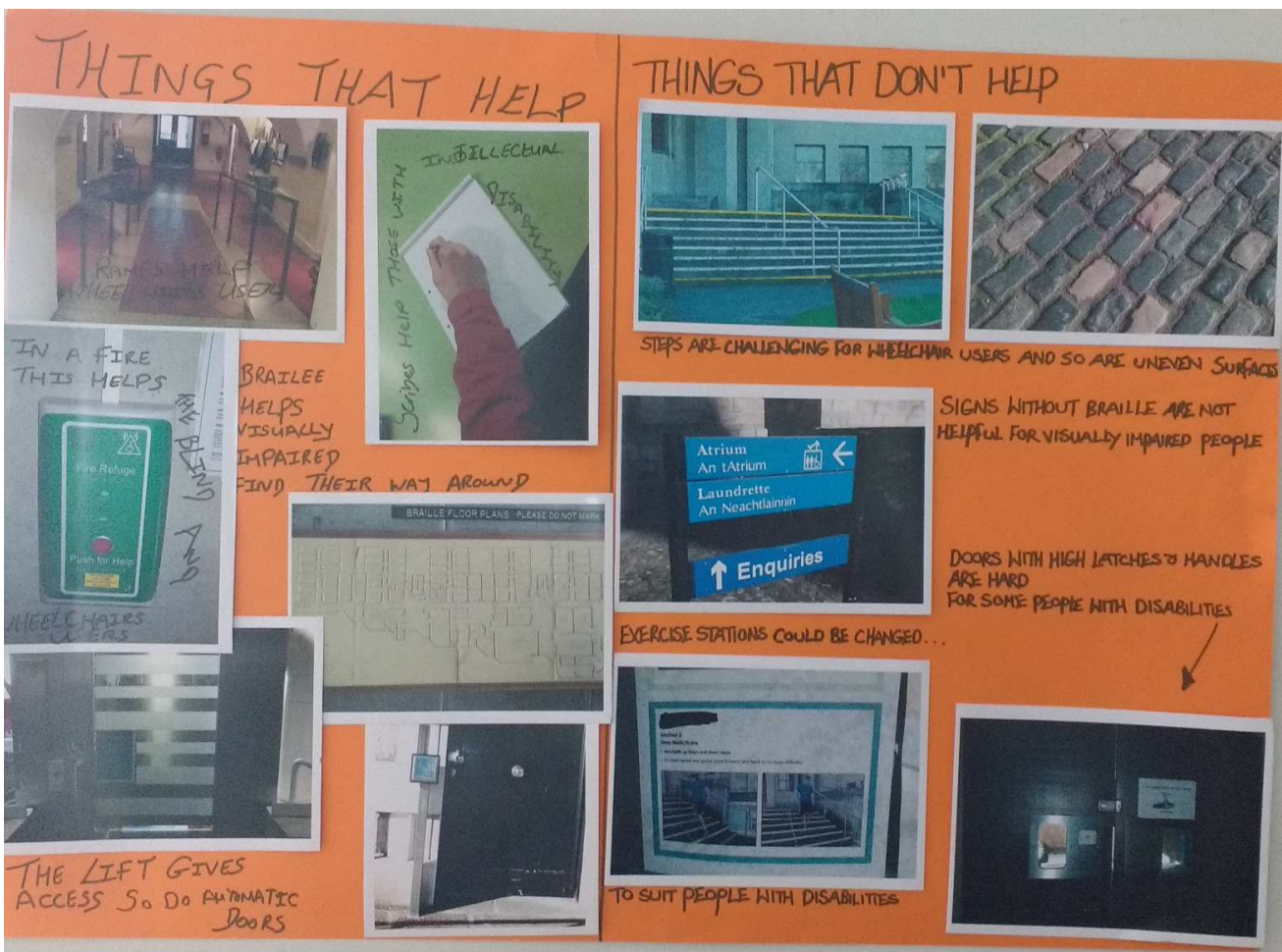

$1061 \times 783 \mathrm{~mm}(72 \times 72$ DPI $)$

36

37

39

40

41

42

43

44

46

47

48

49

50

51 
1 The experience of students with disabilities in university

Table 1: Things we like about college life votes

\begin{tabular}{|c|c|}
\hline Things we like about college life & Number of Votes \\
\hline Socialising & 8 \\
\hline Graduating & 6 \\
\hline Learning & 5 \\
\hline Technology & 5 \\
\hline Sports and being healthy & 4 \\
\hline Architecture & 2 \\
\hline
\end{tabular}

17 
2 The experience of students with disabilities in university

Table 2: Things we dislike about college life votes

\begin{tabular}{|c|c|}
\hline Things we dislike about college life & Number of Votes \\
\hline Studying/exams & 8 \\
\hline Road works/traffic/trains & 8 \\
\hline Ramps help some people but are a hazard to others & 5 \\
\hline Getting up early & 2 \\
\hline Sports & 1 \\
\hline Birds & \\
\hline
\end{tabular}


3 The experience of students with disabilities in university

Table 3: Barriers to participating in college votes

\begin{tabular}{|c|c|}
\hline Barriers to participating in college & Number of Votes \\
\hline Hard to open doors & 8 \\
\hline Steps and stairs & 8 \\
\hline Things too high up & 4 \\
\hline Cobbles stones & 2 \\
\hline Sings are hard to read & 2 \\
\hline Going through the main gates (lots of people) & \\
\hline
\end{tabular}


4 The experience of students with disabilities in university

Table 4: Supports to participating in college votes

\begin{tabular}{|c|c|}
\hline Supports to participating in college life & Number of Votes \\
\hline Classroom Support & 8 \\
\hline Ramps, automatic doors and lifts & 6 \\
\hline Join in sporting games & 5 \\
\hline Services & 4 \\
\hline Going to reception for information and help & 2 \\
\hline Signs and braille maps & 1 \\
\hline Emergency equipment and stations & \\
\hline
\end{tabular}


1. Revision Letter to the Editor

\title{
Revision Letter to the Editor
}

We thank the reviewers for their insightful feedback and have made the required changes as listed below. Please do not hesitate to be in contact if further information is required. We look forward to hearing back about the status of the manuscript.

\section{Referee: 1}

The work created from a participatory approach involving students with learning disabilities is really interesting and positive. I've the following comments:

\section{The title could indicate where the work was conducted (i.e. in a university, in} Ireland).

We added this suggestion to the title. The title now reads "Likes, dislikes, supports and barriers: The experience of students with disabilities in university, in Ireland."

\section{The points of interest should be converted into bullet points.}

We have converted the points of interest into bullet points.

\section{At various points in the work the writing is a little clunky and could do with lifting to a more critically academic style.}

\begin{abstract}
Although we can appreciate the referee's argument here and have made some changes in this regard, the premise of the article was to give voice to students with disabilities. We feel that 'lifting' the writing style throughout the article would compromise that goal. We have added a new section titled 'writing style of paper' to the introduction section and included the paragraph below to highlight our purpose in a clearer fashion:

"We decided to write the paper in accessible format because we wanted to show people with disabilities, researchers, teachers, doctors, and other members of society that people with intellectual disabilities can not only take part in research but can also analyse research data and think critically. The writing style of the paper helps us to show the reader that people with intellectual disabilities had a big part in writing the research paper. During our time in college we learned that people with intellectual disabilities do not have their voices heard and at times are not taken seriously because of their disability. For this reason, it is important that the voices of people with disabilities are included not only in taking part in research projects but also in how research findings are shared with society. This way society can start to
\end{abstract}


2. Revision Letter to the Editor

see people with disabilities, especially intellectual disabilities as having a mind that can think just like someone without an intellectual disability.'

\section{Two research questions are proposed however they could easily slip into four.}

We thank the reviewer for this suggestion, we have reframed the two research questions into four research questions as we feel that this format allows for the paper to be accessible to a wider range of readers.

\section{The work could be considered more of an evaluation than research.}

We appreciate the reviewers comment, however we must respectively disagree as this was a participatory research project rather than an evaluation. The research sought to answer specific questions to generate a better understanding and knowledge about the barriers and supports experienced by students with disabilities in university. There was no evaluation conducted about how the university is supporting students with disabilities.

6. The work refers to 'students with disabilities' and not 'disabled students' this could be explored and justified further in relation to models of disability.

We have added a section about terminology to the Introduction section of the paper and have included the following paragraph:

"Students with disabilities: We decided as a group to refer to students with disabilities as students first and their disability second. It is very common that when society sees someone with a disability they make assumptions about them. For example, they are not smart enough, they could never graduate from college, they could never be an athlete, or they could never have a paying job. But most of the time a person with a disability can do anything they want. It is often the case that society limits them, either through the physical environment, social networks, personal relationships, or the community (this is called the social model of disability)."

7. The work tends to be rather descriptive and needs more critical theory perhaps around rights, identity and potential employment in relation to disability.

We thank the reviewer for this insightful comment. We have included two new subsections named Disability Community and Human Rights in the discussion section of the paper that addresses rights, identity, education and employment as it specifically relates to people with intellectual disabilities. These two new sections read as follows: 
3. Revision Letter to the Editor

\section{"Disability Community}

An interesting finding of our study was that students focused more on physical barriers that could affect a person's ability to participate in university life; while at the same time they identified social and personal factors as key supports needed to be successful in college. We should also mention that when we first started the study it was supposed to focus on the college experience of students with intellectual disabilities, but once we started to collect data it became clear that we were collecting data to support all students with different types of disabilities. This is an important finding because researchers who study disability culture (disability culture is a group of people who have a disability and want to have relationships with other people with disabilities because they experience life the same way) often do not include people with intellectual disabilities as being part of the disability community (Beart, 2005) because a lot of people in society still do not see people with intellectual disabilities as being humans with feelings, dreams, goals, and desires just like other people with or without disabilities (Goodley, 2001; Ferguson \& Ferguson, 2009; Spassiani \& Friedman, 2014).

In our study the group was focused on not only the experience of students with intellectual disability, but also students with all types of disability. Two researchers by the name of Longmore (2000) and Scotch (1998) talk about how people who have a disability often feel connected to other people with a disability because they may have gone through the same kinds of experiences. Our group felt as though they were part of the same disability community as students with physical disabilities and they wanted to make sure the research project helps to support their right to equal access to education as well. Our findings show that future research should look at how people with intellectual disabilities may be included in disability culture as more people with intellectual disabilities may feel the same connection as our group does to the disability community. People with intellectual disabilities need to be part of the disability community because they understand what it is like to feel alone, to not have people believe in their abilities, and have everyone think you cannot be independent. As more people with intellectual disabilities start to live in the community it is important that people with all types of disabilities believe in and support people with 
4. Revision Letter to the Editor

intellectual disabilities. In this way, increased participation and success in important domains, such as higher education, can become a reality.

\section{Human Rights}

The Universal Declaration of Human Rights (United Nations, 1945) was created to make sure that everyone in the world is treated equally no matter what religion you believe in, what language you speak, where you live, what your nationality is, or if you have a disability. However, even with the Universal Declaration of Human Rights people with disabilities were still being denied their rights. For this reason the United Nations' Convention on the Rights of Persons with Disabilities (also known as the CRPD) was created in 2006 and written to make sure that all people with disabilities have equal access to their human rights. The CRPD has a right that is called 'Education for All'. This means that children, adolescents, and adults have the right to access education that is inclusive and of the same quality as people without disabilities. This education should help people with disabilities to learn all of the skills they need in order to participate fully in society and should continue into adulthood if the person wants to continue learning. The CRPD also states that all people with disabilities have the right to employment where they are given the same opportunities and wages as people without disabilities (United Nations, 2006). Although the CRPD has helped people with disabilities, there are still a lot of people with intellectual disabilities who are still denied their right to education and employment. This may be because society does not see the importance of educating people with intellectual disabilities or preparing them for employment because, according to the current model, people with intellectual disabilities cannot be educated and will always be dependent on other people to live. This can be seen in how there are very few systems in place that support people with intellectual disabilities to attend further education or that support them with employment opportunities.

People with intellectual disabilities do want to be independent and that is why it is so important that they get access to high quality education so that they can be competitive for jobs just like other university graduates. We as a group wanted to try to help all students with disabilities because colleges have more people with disabilities now than before. We think this is because people with disabilities want to 
5. Revision Letter to the Editor

learn more and there are more chances for people with disabilities to go to college than there were 20 years ago. This means that colleges need to do more to help people with disabilities to understand things. There can be barriers to going to college so there should be supports too. Colleges can do more to understand everyday struggles and barriers for people with disabilities to make sure that they not only can go to college but that they can successfully complete their programme. Past research has shown that students with intellectual disabilities who go to college are more likely to find paid employment, need fewer supports in the community, and earn more money than do people with intellectual disabilities who do not go to college (Hart, 2006). That is why this research is so important because it directly helps people with disabilities to go to college and be successful."

\section{The methodology needs to perhaps explore participatory and co-production ideas in relation to this study more.}

We have included a more detailed explanation of the participatory and co-production ideas that are involved in the study. This new information can be found under the procedure section of the paper and reads:

"Participatory research design: There are many different styles of research, for this study we used a participatory research design. That is when the participants of the research take an active role in the project like coming up with the research questions, figuring out how to best collect data, analysing the data, and informing the public about your research findings."

And

"After the group analysed the data we presented the findings from the project at a research seminar that was held at the university. We invited important people like the Head of the School of Education, the director of disability services, professors, administrative staff and staff from different student services to come to our research presentation. A total of 70 staff members from around the university attended the seminar. At the seminar, we presented to university staff about the barriers and 
6. Revision Letter to the Editor

supports that we identify for students with disabilities and provided them with suggestions on how to improve the experiences of students with disabilities who go to university. Since the data in our study was collected and analysed by students with disabilities (this type of work is called co-production) we wanted to make sure to share our findings with important staff members of the university, in the hope that future policies can be designed to make sure that they are actually meeting the needs of students with disabilities."

9. It's interesting that the barriers presented here (page 11) tend to be physical in nature not attitudinal etc. (Natasha)

We also found it interesting that the barriers found by participants with intellectual disabilities were physical in nature versus attitudinal. We have highlighted this interesting finding in the Disability Community section of the discussion. It reads:

"An interesting finding of our study was that students focused more on physical barriers that could affect a person's ability to participate in university life; while at the same time they identified social and personal factors as key supports needed to be successful in college. We should also mention that when we first started the study it was supposed to focus on the college experience of students with intellectual disabilities, but once we started to collect data it became clear that we were collecting data to support all students with different types of disabilities. This is an important finding because researchers who study disability culture (disability culture is a group of people who have a disability and want to have relationships with other people with disabilities because they experience life the same way) often do not include people with intellectual disabilities as being part of the disability community (Beart, 2005) because a lot of people in society still do not see people with intellectual disabilities as being humans with feelings, dreams, goals, and desires just like other people with or without disabilities (Goodley, 2001; Ferguson \& Ferguson, 2009; Spassiani \& Friedman, 2014).”

\section{The conclusion needs more work in terms of the development of disability and} educational theory rather than solely the series of recommendations presented.

We have added two new sections to the discussion section of the paper about disability culture, identity and human rights to strengthen the critical engagement of 
our findings to the wider disability context. Please see reviewer comment 7 for these new sections.

\section{Referee: 2}

1. Whilst the intention of this submission is admirable and provides a valuable insight into student experience of university, the authors however, need to reconsider the importance of structuring the document to meet the needs of the intended audience. Hence, further consideration needs to be paid to the style and conventions expected for publication and to amend/refine the article accordingly. This may well require further support (possibly from a tutor) which might challenge one of the authors' original ambitions. However, the importance of addressing this imperative could be an important lesson for aspiring authors.

We appreciate the reviewers comment, however the manuscript was written in accessible format to challenge the way the academic community disseminates research knowledge in peer-reviewed journals. Furthermore, the aim of the paper is to demonstrate to the academic community and wider society that people with intellectual disabilities have the capabilities to engage in research and be key players in disseminating research findings. We have added a new section titled 'writing style of paper' to the introduction section and included the paragraph below to highlight our purpose in a clearer fashion:

"We decided to write the paper in accessible format because we wanted to show people with disabilities, researchers, teachers, doctors, and other members of society that people with intellectual disabilities can not only take part in research but can also analyse research data and think critically. The writing style of the paper helps us to show the reader that people with intellectual disabilities had a big part in writing the research paper. During our time in college we learned that people with intellectual disabilities do not have their voices heard and at times are not taken seriously because of their disability. For this reason, it is important that the voices of people with disabilities are included not only in taking part in research projects but also in how research findings are shared with society. This way society can start to see people with disabilities, especially intellectual disabilities as having a mind that can think just like someone without an intellectual disability."

2. Care also needs to be taken to ensure that the document avoids unnecessary and irritating repetition e.g. Page 3 , second paragraph would benefit by deleting the first sentence.

We have deleted the repetitive sentence on Page 3 and took care to delete unnecessary/repetitive parts of the manuscript. 
3. Clarification also needs to be made between statements and statistics that relate to students in 'college' and those in 'universities'. The two are not synonymous and hence, related statistics need to accommodate this.

The type of higher education institution has been added when referring to cited research throughout the manuscript.

4. It is difficult to understand some of the research outcomes cited - such as the Irish Survey of Student Engagement (page 3 line 57) which identifies the fact that ' $97 \%$ of students spend some time studying every week'. Might it not be expected that all students - by dint of their status - would spend 'some time studying every week'?

This statistic was removed and this section reworded to clarify results of ISSE study.

5. It might also be useful if a distinction could be made between difficulties and barriers that are common to all students (e.g. finding from McCoy et al such as 'paying fees or other costs' page 4 line 13) and those more commonly experienced by students with disabilities? Similarly, is it not likely that all students 'considered academic activities stressful and spend most of their time doing college work' (page 5 para 1 ). The same might be argued regarding the finding that 'tension between classmates' can be equally damaging for all students (page 13 para 1).

Clarifying statements added to these sections. It is true that activities which are challenging for students with disabilities are most likely also challenging for other students, however the cited research only explored the experiences of students with disabilities. The following sentence was added: Although many of the challenges experienced by students with disabilities can be experienced by all students it may be more difficult for students with disabilities to cope with these challenges in addition to managing their disability.

6. It would be useful were inconsistencies or contradictions in research findings to be explored and expanded further e.g. in identifying the theme of 'learning' as the second highest positive outcome, how does this relate to the negative theme of 'studying' as a factor that students dislike? It would be useful to offer further reflections on such issues. Similarly, on page 9 it is argued that 'learning' was seen as important, not least for 'life after college .... and for their personal lives in the future'. Yet, on page 10, it is suggested that 'getting up early' was something that the group did not like. Is this too, not something that would help address their aspirations for the future and as such, might be viewed as a contradiction? Similarly, 'ramps' were seen as hazardous by some whilst others found steps and stairs a barrier. How might this discrepancy be addressed? 
9. Revision Letter to the Editor

We thank the reviewer for bringing to our attention the contradiction in findings. We have added the following two sections to address these concerns:

Added to the discussion section under the academic subtitle: "Our findings also showed that students with intellectual disability may be no different than other students who don't have a disability. For example, students reported that they like attending college because they like to learn new things and understand that a college education will help develop independent life skills and will increase your chances of getting a better paying job, but students dislike studying, taking exams and getting up early, which is common for students to feel regardless of disability."

Added to the discussion section under physical barriers subtitle: "We also found that some students in our research project reported ramps to be hazardous for students who are visually impaired or blind, while other students reported steps and stairs to be a barrier for wheelchair users. The group talked about how each student has their own needs and it is important that the university understand what each student needs to make sure they are successful and safe while on campus."

7. Assertions such as 'Colleges have more money now than before' (page 14 lines $12 \& 13)$ need to be supported with accessible evidence. Similarly, statements such as 'past research has shown....' (page 14 line 24) needs that research cited.

The sentence 'Colleges have more money now than before' was removed when editing discussion. Research is cited: Past research has shown that students with intellectual disabilities who go to college are more likely to find paid employment, need fewer supports in the community, and earn more money than do people with intellectual disabilities who do not go to college (Hart, 2006) 